\title{
Correction to: The dynamic differences between self- and other-oriented mental inferences: An ERP study on a false-belief task
}

Xieshun Wang ${ }^{1} \cdot$ Yanjie $\mathrm{Su}^{1} \cdot$ Min Hong ${ }^{1}$

Published online: 27 May 2021

(C) The Psychonomic Society, Inc. 2021

Correction to: Cognitive, Affective, \& Behavioral Neuroscience https://doi.org/10.3758/s13415-021-00899-5

The original article has been updated to include funding note information.

Publisher's note Springer Nature remains neutral with regard to jurisdictional claims in published maps and institutional affiliations.

The online version of the original article can be found at https://doi.org/ 10.3758/s13415-021-00899-5

Yanjie $\mathrm{Su}$

yjsu@pku.edu.cn

1 School of Psychological and Cognitive Sciences and Beijing Key Laboratory of Behavior and Mental Health, Peking University, 5 Yiheyuan Road, Haidian District, Beijing 100871, China 